\title{
Attitudes of the general population to psychiatric and physical illness
}

\author{
Stephen M. Lawrie
}

\begin{abstract}
Alms and method The attitudes of members of the general population to people with psychiatric and physical illnesses were examined. We took a random sample of $\mathbf{2 8 0}$ members of the general population listed in the phone directory and sent them a brief clinical vignette about a neighbour with either schizophrenia, depression, diabetes or no illness.

Results Only 103 (41\%) of the surveyed general population responded. Some unsolicited comments revealed negative attitudes from a small number of subjects. There were, however, no statistically significant differences in general attitudes to sufferers of psychiatric and physical illnesses suggestive of discrimination against the former. Indeed, respondents showed a general tendency to be more supportive of a neighbour with any iliness than to those without. In a sub-analysis, however, those who knew someone with schizophrenla were significantly less likely to be sympathetic towards them.

Clinical implications We have not detected any general stigmatisation of those with psychiatric disorders, but our results may be attributable to response bias. Discrimination against those with psychiatric disorder may be limited to a relatively small sector of society or may only be manifest in relatively close relationships.
\end{abstract}

Stigmatising attitudes towards patients with psychiatric disorders may now be the largest single obstacle to improving their quality of life. Negative or discriminatory attitudes may be expressed by family members, friends, the general public, employers and even doctors (Lawrie, 1999a). A recent survey of those with 'mental health problems' found that approxdmately a half had been abused or harassed in public, and a third had been dismissed or forced to resign from jobs (Read \& Baker, 1996). Not only does such discrimination impair patients' chances of being able to re-integrate socially, there is also good evidence that criticism or hostility can increase relapse rates (Brown et al, 1972). The most common reaction of the general public, however, is a social distancing or avoldance (Rabkin, 1974; Bhugra, 1989). Such behaviour and attitudes appear to be related to a fear of and an ignorance about psychiatric disorders (Brockington et al, 1993; Wolff et al, 1996) but there are few recent UK studies of general population attitudes.

Using case vignettes, we have previously reported that general practitioners were less willing to treat a patient with a past history of schizophrenia than an otherwise identical patient without that diagnosis (Lawrie et al, 1996), and that this was not simply a general attitude towards those with any chronic or psychiatric condition (Lawrie et al, 1998). We therefore sought to develop that approach, by conducting a randomised trial of the attitudes of members of the general population to patients with different psychiatric as opposed to medical conditions.

\section{The study}

We randomly selected 280 members of the general population identified as the first name on alternate pages of the Lothian telephone directory. Each was sent, in turn, one of four brief case vignettes that were identical apart from mention of a past medical history of schizophrenia or depression or diabetes or no lllness. Subjects were asked to imagine that:

A young family have moved in next door. The woman is a 30-year-old married housewife, with a five-yearold child. One of your friends has told you that she has a two-year history of schizophrenia/depression/ diabetes for which she is receiving treatment from her doctor. (Note, for the fourth 'no lliness' vignette, this third sentence was omitted.) One morning she comes round to ask you if she can borrow some sugar. She tells you that she has not been sleeping well and has been very tired since moving house.

We then asked the subjects to indicate their level of agreement (0-6) with 12 questions based on the vignette (see Table 1), and asked them several questions about themselves (see Table 2) to see if certain personal characteristics influenced responses. Social class was coded according to the Standard Occupational Classification (Office of Population Censuses and Surveys, 1990). Statistical testing employed non-parametric 
Table 1. Levels of agreement (0-6) - median score (inter-quartile range)

\begin{tabular}{|c|c|c|c|c|c|}
\hline Statement & $\begin{array}{l}\text { Person with } \\
\text { schizophrenia } \\
\text { (S) }\end{array}$ & $\begin{array}{l}\text { Person with } \\
\text { depression } \\
\text { (De) }\end{array}$ & $\begin{array}{l}\text { Person with } \\
\text { diabetes } \\
\text { (Di) }\end{array}$ & $\begin{array}{l}\text { Healthy } \\
\text { person } \\
\text { (H) }\end{array}$ & $\begin{array}{l}\text { Kruskal-Woillis } \\
\text { P value and } \\
\text { post hoc teots }\end{array}$ \\
\hline $\begin{array}{l}\text { 1. You would be pleased to } \\
\text { meet her }\end{array}$ & $5(3-6)$ & $5(4-6)$ & $6(4-6)$ & $5(3-6)$ & 0.6 \\
\hline $\begin{array}{l}\text { 2. You would be happy to } \\
\text { give her the sugar }\end{array}$ & $6(5-6)$ & $6(5.5-6)$ & $5(1-6)$ & $6(6-6)$ & $\begin{array}{l}0.007 \\
\mathrm{DI}<\mathrm{S}, \mathrm{D} \Theta, \mathrm{H}\end{array}$ \\
\hline $\begin{array}{l}\text { 3. You would offer her a } \\
\text { cup of tea }\end{array}$ & $4(2-5)$ & $5(3-6)$ & $4(3-6)$ & $2(0-5)$ & $\begin{array}{l}0.01 \\
H<D \Theta, D i\end{array}$ \\
\hline $\begin{array}{l}\text { 4. You would be happy to } \\
\text { go around to her house } \\
\text { sometime }\end{array}$ & $4(1-5)$ & $5(2-6)$ & $3(2-6)$ & $3(1-4.5)$ & 0.1 \\
\hline $\begin{array}{l}\text { 5. You would offer to look } \\
\text { after her child if she had to } \\
\text { go to the doctor }\end{array}$ & $4(1-6)$ & $4.5(3-6)$ & $5(3-6)$ & $5(2-6)$ & 0.9 \\
\hline $\begin{array}{l}\text { 6. You would be concerned } \\
\text { about the child }\end{array}$ & $2(1-4)$ & $3.5(2-6)$ & $3(1-6)$ & $3(0-4)$ & 0.3 \\
\hline $\begin{array}{l}\text { 7. You would feel comfortable } \\
\text { asking about her personal life }\end{array}$ & $1(0-2)$ & $1(0-3)$ & $1.5(0-3)$ & $3(0-4)$ & 0.7 \\
\hline $\begin{array}{l}\text { 8. You would be worried that } \\
\text { she may have a drink problem }\end{array}$ & $2(0-3.5)$ & $2(0-3)$ & $0.5(0-3)$ & $0(0-0)$ & $\begin{array}{l}0.004 \\
H<S, D \Theta, D I\end{array}$ \\
\hline $\begin{array}{l}\text { 9. You would ask her to go out } \\
\text { with you and your friends } \\
\text { sometime }\end{array}$ & $1(0-3)$ & $2(0-5)$ & $1(0-3)$ & $0(0-3)$ & 0.08 \\
\hline $\begin{array}{l}\text { 10. She would arouse your } \\
\text { sympathy }\end{array}$ & $3(2-4)$ & $4(3-5)$ & $3(1-5)$ & $3(1-4)$ & 0.09 \\
\hline $\begin{array}{l}\text { 11. You would think that she } \\
\text { could deal with her own } \\
\text { problems }\end{array}$ & $3(2-3)$ & $3(0-3)$ & $3(1-4)$ & $3(3-4.5)$ & 0.2 \\
\hline $\begin{array}{l}\text { 12. You would be happy to let her } \\
\text { look after your children }\end{array}$ & $1(0-3)$ & $1(0-3)$ & $3(0.5-4)$ & $0(0-3)$ & 0.2 \\
\hline
\end{tabular}

overall Kruskal-Wallis tests followed by post hoc Mann-Whitney $U$-tests to examine the hypothesis that any negative attitudes would be most evident in those sent the vignette of the woman with schizophrenia.

\section{Findings}

A total of 103 members of the general public returned questionnaires - a response rate of $41 \%$ (21 had moved or died). The demographics of respondents are shown in Table 2. The only statistically significant difference was in the proportion of respondents knowing someone affected with a particular condition $(P=0.02)$, with a predictably smaller number knowing someone with schizophrenia as compared with depression or diabetes.

A few respondents gave unsolicited comments about the vignettes, which ranged from the generally open-minded or concerned to the frankly antagonistic. Indeed, three of the four in response to the subject with schizophrenia were critical: "I do not want any kind of mentally disturbed person living in my neighbourhood"; "My mother had some of these people living next

Table 2. General population demographics

\begin{tabular}{llllll}
\hline & Schizophrenia & Depression & Dlabetes & Healthy & P value \\
\hline $\begin{array}{l}\text { Responders }(n) \\
\text { Median age, years }\end{array}$ & 25 & 27 & 28 & 21 & - \\
$\quad$ (inter-quartile range) & $39(32-64)$ & $50(43-63)$ & $54(47-70)$ & $48(34-68)$ & 0.2 \\
$\begin{array}{l}\text { Gender (male/female) } \\
\text { Social class }\end{array}$ & $17 / 8$ & $14 / 15$ & $16 / 12$ & $11 / 10$ & 0.5 \\
(median, inter-quartile range) & $4(2-6.5)$ & $3(2-7)$ & $4.5(2.5-7)$ & $4(2-7)$ & 0.6 \\
$\begin{array}{l}\text { Married/single } \\
\text { Urban/rural }\end{array}$ & $16 / 9$ & $18 / 11$ & $18 / 10$ & $15 / 6$ & 0.9 \\
Know anyone affected? & $18 / 7$ & $21 / 8$ & $16 / 12$ & $16 / 5$ & 0.5 \\
$\quad$ (yes/no) & $10 / 15$ & $24 / 5$ & $21 / 7$ & - & 0.02 \\
\hline
\end{tabular}


door as part of community care ... it didn't work at all...these people need hospital"; "I had to care for an in-law with schizophrenia... neither of us liked it"; and "My responses are nothing to do with her lliness, I would offer tea to any neighbour... but I don't know any well enough to discuss personal issues". In contrast, none of the five spontaneous comments from those responding to the patient with depression were overtly negative, generally saying they would not judge someone until they knew them better, and one was positively supportive: "Jesus is the answer...the truth and life...tell her of Jesus! Hallelujah! AMEN". Two essentially neutral comments were received with reference to the patient with diabetes and one about the women with no medical or psychiatric history.

The responses to the questionnaire, grouped by vignette, are displayed in Table 1 and show overall differences in the questions about: giving the woman the sugar requested; offering her a cup of tea; and the possibility of a drink problem. Specifically, these differences were attributable to people being less willing to give the sugar to the diabetic than those with other diagnoses, apparently being more sociable (offering tea) towards those with depression or diabetes than healthy controls and believing that all those with chronic illnesses were more likely to have a drink problem than controls (post hoc differences $P<0.05$, see Table 1 ).

Finally, the effect of knowing affected subjects was examined by contrasting those who did or did not know someone with schizophrenia, and secondly by re-analysing all questions only in those who knew someone with schizophrenia/ depression/diabetes. Intriguingly, both analyses showed that those who knew someone with schizophrenia were less likely to be sympathetic towards them $(P<0.05)$, whereas the pattern of other results remained essentially unchanged.

\section{Comment}

Those members of the general population who responded to the vignettes appear to make little attitudinal distinction between those with chronic psychiatric or medical disorders, although the poor response rate means that there is low power to detect statistically significant differences between those allocated different vignettes and raises the possibility of response bias. The results from responders to any postal survey may not be applicable to all members of the public-specifically, nonresponders to our survey may have had more negative attitudes that may have been associated with their non-response. On the other hand, only one postal sweep of the sample was performed, to which a response rate of about $50 \%$ is typical, and there is no particular reason to believe that those who would have responded to a second sweep would have markedly different attitudes. There was no information about non-responders, however, and any conclusions based on such a low response rate must be very cautious. Using the telephone directory as a means of identifying members of the general population may skew the sample to upper social classes, but this does not appear to apply to those responding to the vignettes. Despite low power, some statistically significant differences were detected as well as some trends to significance. Therefore, I believe that the results merit publication, particularly as there are few recent studies of attitudes in the general population and because a comparison with the attitudes of general practitioners in our previous studies is possible and potentially instructive.

The significant differences on the 'cup of tea' question, and the trends to significance on questions regarding sympathy and socialising, suggest that the general population are prepared to reduce their usual 'social distance' with those who are depressed (and diabetic). The patients with schizophrenia were treated like the healthy control. Taken together, these responses suggest that the public may offer support to both the 'physically' and 'mentally' ill, either at times of stress or in general. They may see this as important given that patients with any chronic illness were expected to drink more than those in good health, as revealed by responses to the alcohol question. Thus, the general population appear to be broadly tolerant of the sufferers of chronic psychiatric disorders, as others have recently reported (Brockington et al, 1993: Priest et al, 1996). Indeed, even the pattern of scores on the questions not showing statistically significant differences are in keeping with this view. It may be therefore that negative attitudes are only found in a relatively small sector of society. although there is some evidence that the public are more fearful and avoidant when patients are acutely ill (Penn et al, 1994). In addition, being 'a good neighbour' and socialising with psychiatric patients may be seen as generally safe, whereas closer relationships may be seen as more dangerous (Rabkin, 1974: Bhugra, 1989).

This survey was undertaken in late 1996, at a time of much negative media coverage of psychiatry and schizophrenia in particular. I have reported on this in another article (Lawrie. $1999 \mathrm{~b}$ ). This background to our survey makes our failure to find substantial evidence of discrimination all the more notable.

It is remarkable, and sad, that people who knew patients with schizophrenia were less likely to be sympathetic towards them than those who did not know such people or those who knew the sufferers of depression or diabetes. It is difficult 
to see how this could be attributable to an aspect of our vignette or to any selective response bias. We think it more likely that this rather counterintuitive result reflects an ignorance of the causes of the illness and a tendency to blame the sufferer. It is for example known that relatives of those with schizophrenia find the negative symptoms of the disease particularly difficult to tolerate - tending to regard a lack of drive or energy as laziness rather than illness (Kuipers \& Bebbington, 1987).

Our recent study on the attitudes of general practitioners (Lawrie et al, 1998a) used vignettes with patients of the same age, gender and diagnoses as in the current study. Questions 1 , 6. 8 and 10 were almost identical in the two surveys. General practitioners were less happy to have the patient with schizophrenia on their list and were more likely to be concerned about the child's welfare, but did not distinguish between the groups in terms of likely excessive alcohol consumption. These findings suggest medical discrimination, but could also reflect clinical realities. However, Read \& Baker (1996) found that one half of their sample felt badly treated by health care services and one-third complained that their own doctor had treated them unfairly. We have also conducted brief semi-structured interviews with a small number of in-patients with psychosis, who reported that doctors (including psychiatrists) were more likely to discriminate against them than any other social group (Lawrie et al, 1998b). Taken together, these findings suggest that doctors may actually be more critical of psychiatric patients than the general population.

\section{Acknowledgements}

This work was conducted as part of a problembased learning project with first year medical students at Edinburgh University. Katherine Martin, Gregor McNeill, Jennifer Drife, Patrick
Chrystie, Adam Reid, Pensee Wu, Shafic Nammary and Joanna Ball all assisted in the design and execution of the project. We are grateful to all the members of the public who participated in these studies.

\section{References}

Brockington, I. F., Hall, P., Levings, J., et al (1993) The community's tolerance of the mentally ill. British Journal of Psychiatry. 162, 93-99.

Brown, G. W., BIRLEY, J. L. T., WING, J. K. (1972) Influence of family life on the course of schizophrenic disorders. A replication. British Journal of Psychiatry. 121, 241-258.

BHugRA, D. (1989) Attitudes towards mental illness. Acta Psychiatrica Scandinavica, 80, 1-12.

KutPers, L. \& BEBbington, P. (1987) Living with Mental Illness. London: Souvenir Press.

LAWRIE, S. M. (1999a) Stigmatisation of psychiatric disorder. Psychiatric Bulletin. 23, 129-131.

- (1999b) Newspaper coverage of psychiatric and physical lliness. Psychiatric Bulletin. 23, in press.

-. PARSONS, C.. PATRICK. J., et al (1996) A controlled trial of general practitioners' attitudes to patients with schizophrenia. Health Bulletin. 84. 201-203.

- Martin, K., McNelu, G., et al (1998) General practitioners attitudes to psychlatric and physical illness. Psychological Medicine, 28, 1463-1467.

OFFice of POPUIATION CENSUSES AND SURVEYS (1990) Standard Occupational Classification. London: HMSO.

PEnN, D. L., GUYNAN, K., DAIL, T., et al (1994) Dispelling the stigma of schizophrenia: what sort of information is best? Schizophrenia Bulletin. 20, 567-577.

Priest, R. G., Vize, C., RoBerTs, A., et al (1996) Lay people's attitudes to treatment of depression: results of opinion poll for defeat depression campaign just before its launch. British Medical Journal, 313, 858-859.

RABKIN, J. (1974) Public attitudes toward mental illness: a review of the literature. Schizophrenia Bulletin, 10, 9-33.

READ, J. \& BAKER, S. (1996) Not Just Sticks and Stones. London: Mind.

WolfF, G., PATHARE, S., Craig, T., et al (1996) Community attitudes to mental illness. British Joumal of Psychiatry. 168, 183-190.

Stephen M. Lawrie, Senior Clinical Research Fellow, Royal Edinburgh Hospital, Edinburgh EH10 5HF 